\title{
MONGOLIAN SPOT
}

Authors: Roshan Bista, MBBS, Tribhuvan University, Institute of Medicine,

Kathmandu, Nepal

Prativa Pandey, MBBS, Tribhuvan University, Institute of Medicine, Kathmandu,

Nepal

Corresponding author: Roshan Bista, Fayetteville, North Carolina, USA

E-mail: roshanbistaiom@gmail.com

\section{PEER REVIEWED ARTICLE, VOL. 1, NR. 1, p. 12-18 PUBLISHED 27.11.2014}

\section{Abstract}

Colorful skin spots on a pediatric patient can easily be mistaken as signs of child abuse. Professionals should therefore gain knowledge about Mongolian spots; also known as Mongolian blue spots. These are flat, congenital and benign birthmarks, commonly located in sacro-coccygeal or lumbar area of an infant. Child abuse is a major public health problem across the world. The most common manifestations of physical child abuse are cutaneous, and their recognition and differential diagnosis are of great importance. Mongolian spots may appear as signs of child abuse; however, Mongolian spots are harmless.

Keywords: Birthmark, Child abuse, Mongolian spot, Mongolian spots, Skin signs

\section{Introduction}

Mongolian spots (MS) refers to a macular blue-gray pigmentation usually on the sacral area of healthy infants. MS is usually present at birth or appears within the first weeks of life. MS can be of various shapes and sizes, they may be single or multiple, they might vary from a few to more than $20 \mathrm{~cm}$, and usually they involve $<5 \%$ of the total body surface area(Gupta, 2013). The most common color is blue, although they can be blue-gray, blue-black or even deep brown. Pigmentation is most intense at the age Radiography Open 2014 Vol. 1

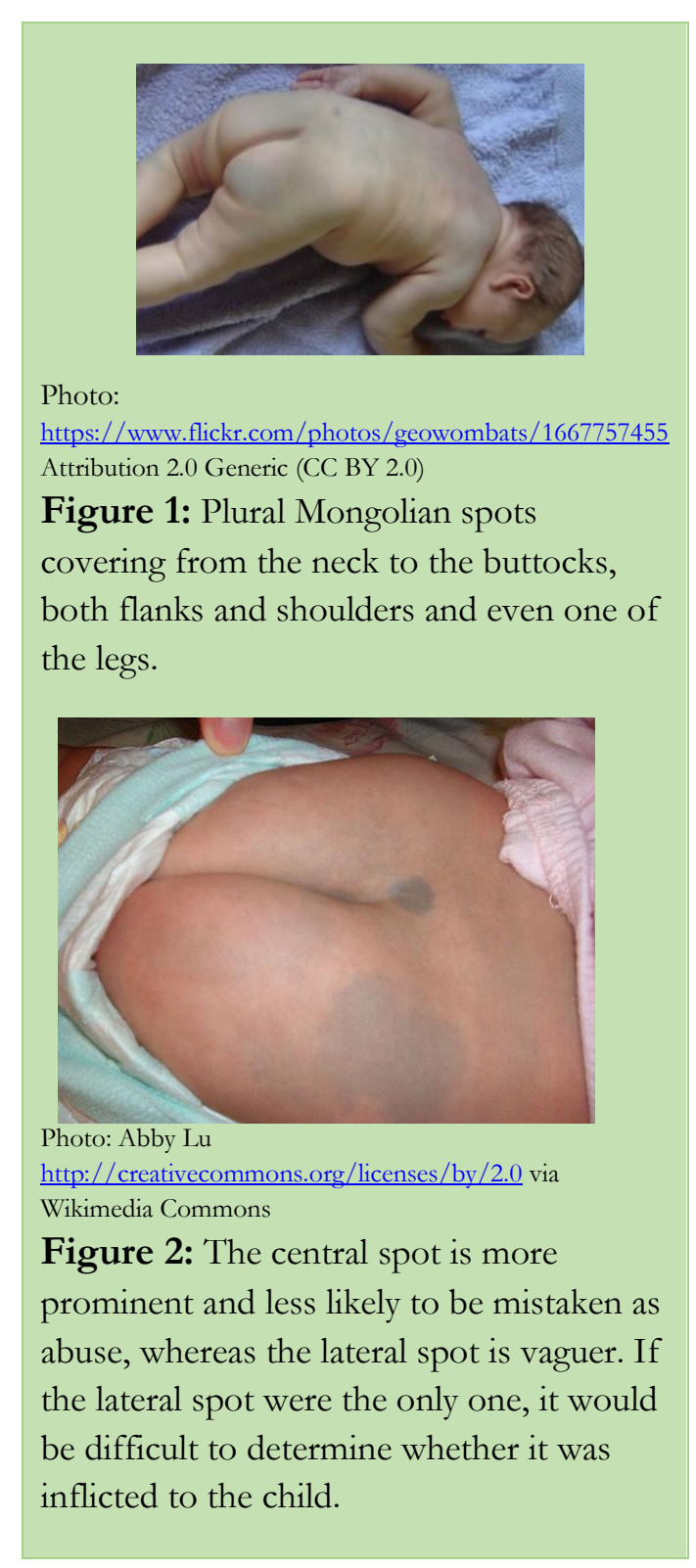

ISSN: 2387-3345 
of one year and gradually fades thereafter. It normally disappears three to five years after birth and almost always by puberty(Gupta, 2013), however they can also persist for life.

\section{Material and methods}

Searches of the following databases was performed, UpToDate, PubMed and Google scholar. Key words as Birthmark, Child abuse, Inborn errors of metabolism, and Mongolian spot were used.

In this review, we provide an overview regarding epidemiologic distribution among countries and genders; further describe the cutaneous manifestations characteristics and distribution, and the cultural reference. The latter part of the article outlines key differences between MS and child abuse.

\section{Why Mongolian?}

Such spots were discovered by a German medical doctor and anthropologist, Erwin Bälz, who settled down in Japan (Baelz.E, 1885). He found that MS were common in any part of the body of dark-skinned babies, believing them to be characteristic of Mongoloid races; thereby the name.

\section{Ethnic distribution}

A unique feature of MS is the varying prevalence depend on ethnicity of the population.

Depending on the nation, the blue spot also occurs amongst one to ten percent of any other ethnic group. This condition is most common among Asians and Africans, and less common in Caucasians. MS has also been observed among other East, Southeast, North, and Central Asian peoples, Micronesians, Polynesians, Amerindians, East Africans, Latin Americans, Caribbean's of mixed-race descent, and Turkish people (Ayten Egemen, 2006).

\section{Frequency}

The frequency varies a lot, reported as being $25 \%$ in Australians, $7 \%$ in Jews, $12 \%$ in Arabs and $13-25 \%$ in Turkish babies(Ayten Egemen, 2006), and 75\% of Nigerians and 50\% of Brazilians. The frequency varied from $10-70 \%$ in Iranian neonates; and were $80 \%$ in the Japanese, $62 \%$ in the Taiwanese and 86-100\% in the Chinese newborns (Leung, 1988).

Two studies conducted in Punjab and Chandigarh (North India) found the frequency of MS to be $60 \%$ and $62 \%$ respectively (Gupta, 2013). On the other hand, three studies conducted in Karnataka (South India) on cutaneous lesions in the newborns found the frequency of MS to be 69\%, 72\% and 89\%, respectively, whereas a similar study from Pondicherry (South India) found it to be $78 \%$.

A total of 2.305 newborns were examined over 2 years, 2004-2006, at Shariati Hospital, Tehran, Iran; and MS were found in 262 neonates (11.4\%); while altogether 71,3\% MS were found by Moosavi and Hosseini that examined 1,000 newborns delivered at two universities and being in their first 3 days of lives in Ahvaz, Iran, years 2002-2003 (Reza, 2010). 


\section{R. Bista, P. Pandey \\ MONGOLIAN SPOT}

\section{Gender distribution}

A comparison study of 92 Chinese Canadian newborn infants (49 boys and 43 girls) and 1633 Chinese Canadian children ( 819 boys and 814 girls) found that MS were present in all newborns and disappeared slowly until 6 years of age when the rate of disappearance increased (Leung, 1988). The overall incidence was $58 \%$ in boys and $53 \%$ in girls. Both sexes are equally affected states Gupta (Gupta, 2013).

\section{Physiology and pathophysiology}

Besides Mongolian spots, birthmarks have been called variously, such as Cafe au lait spot, hemangioma, nevus and strawberry marks. There are two types of birthmarks; vascular red birthmarks that consists of blood vessels that are not correctly formed, and pigmented birthmarks that are made of a cluster of pigment cells which cause color in skin. They can become visible in many different colors from tan to brown, gray to black, or even blue James WD, 2011). MS is a birthmark, a benignant skin colored area, congenital hyper-pigmented macules or patches. No special test requires for diagnosing a Mongolian spot, as they are identified simply by looking. MS is a developmental condition exclusively involving the skin. Mongolian spots result from entrapment of melanocytes in the dermis because of arrested transdermal migration from the neural crest into the epidermis(Ashrafi, Shabanian, Mohammadi, \& Kavusi, 2006). Histologically, it is explained as these melanocytes in the lower dermis failed to migrate to the dermal-epidermal junction during fetal life. The discoloration is usually homogenous. Although regarded as benign, recent data suggest that MS may associated with inborn errors of metabolism, which the most common being Hurler syndrome; neurocristopathie as refers to a disorder characterized by abnormalities in neural crest migration, and cleft lip (Igawa, Ohura, Sugihara, Ishikawa, \& Kumakiri, 1994). A literature review revealed 39 cases of lysosomal storage disease associated with dermal melanocytosis; 24 patients had Hurler disease(Ashrafi et al., 2006). Allthough typical and limited Mongolian spots are benign skin markings at birth which fade and disappear as the child grows, extensive Mongolian spots deserve special attention as possible indications of ijassociated inborn error of metabolism. A few cases of extensive Mongolian spots in association with inheritable storage diseases have been reported(Ashrafi et al., 2006). Some hypotheses has been put forward, but further investigation is necessary to eliminate causative factors. This report describes three infants with generalized Mongolian spots, two infants with GM1 gangliosidosis type 1, and one in association with Hurler syndrome. Findings of generalized Mongolian spots in newborns may lead to an early detection and early treatment before irreversible organ damage occurs (Ashrafi et al., 2006). 


\section{Shape, size and localizations}

MS is of varying shape and size. MS usually resolve by early childhood and treatment. It is no need for treatment if they are located in the sacral area. It is commonly located in sacrococcygeal or lumbar area of a child. MS involves the lumbosacral area, but the buttocks, flanks, and shoulders can also be affected in extensive lesions. Sometimes, they can cover more than $20 \mathrm{~cm}$ length of the body surface. In the study of Chinese Canadian newborn infants and Chinese Canadian children, by Leung, 1988(Leung, 1988), the most frequent site of involvement was the sacro-coccygeal area and both sides of the body was equally affected. Spots were not found on the face, neck,
Table 1: Distribution of localizations of Mongolian spots on the body surface

$\begin{array}{ll}\begin{array}{ll}\text { Mongolian spot } \\ (\mathrm{n}=1.907)\end{array} & \text { No. of cases }(\%) \\ \text { Gluteal and trunk } & 1.855(97,3) \\ \text { Upper extremeties } & 20(1,0) \\ \text { Lower extremeties } & 15(0,8 \\ \text { Chest and back } & 13(0,7) \\ \text { Head and neck } & 3(0,2) \\ & \text { Nam, Woo Seung, } 2014\end{array}$
perianal area, palms, or soles. Blue nevi, nevi of Ota, and bruises should be differentiated (Numabe, 2003). Careful observation by a specialist will easily allow differentiation. Table 1 shows Location of Mongolian Spots as presented by Seung Woo Nam et.al. (Nam, Woo Seung, 2014)

The most frequent site of involvement from the Iranian studies, were the sacral, followed by the gluteal area(Reza, 2010). Figure 1 and Figure 2 show two different children, and at a different age. Both figures illustrate the most common localizations, distributions and the color differing of MS.

\section{Unusual localizations}

In case of MS on unusual places, they should be documented at birth to avoid confusion with other dermal melanocytosis and bruises secondary to child abuse; which cover localization of MS over occiput, temple, mandibular area and the shoulders.

\section{Colors}

The most common color is blue, although they can be blue-gray, blue-black or even deep brown. The spot colors also depends on the colors of the skin itself, as e.g. variation from grayish blue to grayish black. (James WD, 2011)

Age

The distribution of 1907 Mongolian spots was reported in a study of incidence of birthmarks in Korean newborn infants 2014 (Nam, Seung Woo, 2014 ); the 94\% having MS had a gestational 
age at full-term; while preterm and post-term together was $6 \%$. The children with MS were at normal birthweight and delivery mode were mainly vaginal delivery. They are present at birth, and most of them disappear at an age of 3-4years, still some can persist longer (Gupta, 2013).

\section{Cultural references}

Through the centuries, MS have been the subject of many stories and controversies, both biologically and anthropologically.(Cordova, 1981) Earliest known accounts of MS date back to Hippocrates, who believed that a blow to the pregnant mother's abdomen; was stated as a mark at the corresponding place in the newborn. In Japan, a MS is referred to in the Japanese idiom shiri ga aoi, with the meaning "to have a blue butt", which is a reference to immaturity or inexperience. In Mexico, its name is the "green butt". In Korea, there are an explanation that if a MS bruise is formed under 'Samshin Halmoni' a shaman spirit who play around the child birth, has beaten the baby's butt as help for a baby to go out from his or her mother.

Radiography Open 2014 Vol. 1
Table 2: Differentials between Mongolian spots and bruise by abuse (Numabe, H. 2003)

\begin{tabular}{|c|c|c|}
\hline & Mongolian spots & Bruise by abuse \\
\hline 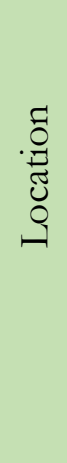 & $\begin{array}{l}\text { Frequent/Often: } \\
\text { Sacro-coccygeal area, } \\
\text { lower back spine, buttocks } \\
\text { lateral abdomen, } \\
\text { shoulders, upper arms, } \\
\text { wrists, legs } \\
\text { Rare: } \\
\text { palms, soles, face, neck }\end{array}$ & Anywhere \\
\hline$\frac{\dot{0}}{0}$ & $\begin{array}{l}\text { Blue, bluish-gray, bluish- } \\
\text { green, bluish-black }\end{array}$ & $\begin{array}{l}\text { Changes over time: } \\
\text { red-purple } \rightarrow \text { brownish-red } \rightarrow \\
\text { fades as healing } \rightarrow \text { lesions may } \\
\text { become hemorrhagic or necrotic }\end{array}$ \\
\hline 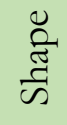 & $\begin{array}{l}\text { Usually irregular and edges } \\
\text { are indistinct }\end{array}$ & $\begin{array}{l}\text { Often reflects shape of object } \\
\text { used, such as hands or belt }\end{array}$ \\
\hline $\begin{array}{l}\check{\Xi} \\
\stackrel{\Xi}{\Xi} \\
\text { Z }\end{array}$ & One or several & $\begin{array}{l}\text { Usually many sometimes } \\
\text { clustered, mix of various healing } \\
\text { stages }\end{array}$ \\
\hline 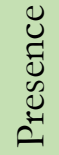 & Usually present at birth & $\begin{array}{l}\text { Regularly occur after absence - } \\
\text { weekends or vacations }\end{array}$ \\
\hline 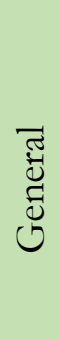 & Normal & $\begin{array}{l}\text { Nervous, anxiety, scared, short } \\
\text { stature, taciturn (inclined to } \\
\text { silence), undernourishment, other } \\
\text { injuries (black eyes, burns, } \\
\text { humerus fractures, tibia fractures, } \\
\text { ligatures) }\end{array}$ \\
\hline
\end{tabular}

ISSN: 2387-3345 
In the comedy manga series Joshiraku written by Kōji Kumeta, as well as in its anime adaptation, the character Marii Buratei is known to have a Mongolian spot. In one sketch, a westerner notices the spot and mistakes it for child abuse, blaming "barbarian Japanese" and taking Marii to "safety" abroad, against her wishes.

As MS might be genetic, parents might have experienced the same spots. Parents of adopted children may feel anxious, so it should be explained them. It is easy to calm them down when they get to hear no treatment needs as the spots most often will fade away within a couple of years.

\section{Mongolian spots versus physical signs of abuse}

Occasionally, Mongolian spots can be mistaken as bruises caused by child abuse. Child abuse is a major public health problem all over the world. There are four major types of abuse: physical abuse, sexual abuse, emotional abuse and neglect. The most common manifestations of child abuse are cutaneous and their recognition; and differential diagnosis is of great importance. Clinicians, especially dermatologists, should be alert about the skin lesions of child abuse.

Atypical localization and shape and presence of many Mongolian spots necessitate the differential diagnosis from dermatologic diseases as well as from child abuse (Ayten Egemen, 2006; Numabe, 2003). In the diagnosis and management of child abuse, a multidisciplinary approach with ethical and legal procedures is necessary. A good clinical history and physical examination can be a help to attempt get to a right diagnosis. Careful observation by a specialist will easily allow differentiation. Differentials between Mongolian spot and bruise by abuse are shown in Table 2 .

\section{Conclusion}

Though Mongolian spots are common birthmarks, their occurrence should be properly explained when parents are anxious. Along with that, it should be taken in consideration to rule out serious hereditary diseases. Last, but not the least, one should be able to differentiate it from the bruises of child abuse. 


\section{R. Bista, P. Pandey \\ MONGOLIAN SPOT}

\section{References}

Ashrafi, M. R., Shabanian, R., Mohammadi, M., \& Kavusi, S. (2006). Extensive Mongolian Spots: A Clinical Sign Merits Special Attention. Pediatric Neurology, 34(2), 143-145.

http://dx.doi.org/10.1016/i.pediatrneurol.2005.07.010

Ayten Egemen, T. İ., Serap Ergör, Gülgün Mete Asar, Özge Y1lmaz (2006). Frequency and characteristics of Mongolian spots among Turkish children in Aegean region. The Turkish Journal of Pediatrics, 48(3), 232-236.

Baelz.E. (1885). Die koerperlichen Eigenschaften der Japaner. . Mittheil.d.deusch Gesell.f.Naturu-Voelkerheilkunde Ostasiens. Bd.4.H.32.

Cordova, A. (1981). The Mongolian spot: A study of ethnic differences and a literature review. Clinical Pediatrics. 20(11),714-719 http://dx.doi.org/10.1177/000992288102001105

Gupta, D., Thappa, D. M. (2013). Mongolian Spots-A Prospective Study. Pediatric Dermatology, 30(6), 683-688. http://dx.doi.org/10.1111/pde.12191

Igawa, H. H., Ohura, T., Sugihara, T., Ishikawa, T., \& Kumakiri, M. (1994). Cleft lip mongolian spot: Mongolian spot associated with cleft lip. Journal of the American Academy of Dermatology, 30(4), 566-569. http://dx.doi.org/10.1016/S0190-9622(94)70063-X

James WD, B. T., Elston DM, eds. . (2011). Andrews' Diseases of the Skin: Clinical Dermatology (. Ed. Vol. Chapter 28). Philadelphia: Saunders Elsevier.

Leung, A. (1988). Mongolian spots in Chinese children. International Journal of Dermatology, 27(2),106-108. http://dx.doi.org/10.1111/j.1365-4362.1988.tb01282.x

Numabe, H. (2003, 2003). Spotting Mongolian Spots [Child Fleck] Birthmark. NOT Bruise. NOT Abuse. About Mongolian Spots. Examples of Mongolian Spots. Differential Diagnosis. . Retrieved 28.10., 2014, from http://www.tokyo-med.ac.jp/genet/msp/index.htm

Reza, A. M., Farahnaz, G.Z., Hamideh, S., Alinaghi, S.A.S., Saeed, Z., Mostafa, H. (2010). Incidence of mongolian spots and its common sites at two university hospitals in Tehran, Iran. Pediatric Dermatology, 27 (4), 397-398. http://dx.doi.org/10.1111/j.1525-1470.2010.01168.x

Nam, Seung Woo; Ko, Sun Young; Lee, Yeon Kyung, Shin, Son Moon, and Kim, En Hyung (2014). The Incidence of Birthmarks in Korean Newborn Infants. Neonatal Medicine, 21(3):151157 http://dx.doi.org/10.5385/nm.2014.21.3.151 